\title{
USE OF MODERN CLOUD SERVICES IN RADIOLOGICAL DIAGNOSTICS TRAINING
}

DOI: 10.36740/WLek202103205

\author{
Natalia V. Stuchynska, Igor V. Belous, Pavlo V. Mykytenko \\ BOGOMOLETS NATIONAL MEDICAL UNIVERSITY, KYIV, UKRAINE
}

\begin{abstract}
The aim: Is to present and substantiate approaches to the organization of radiation diagnostics training using cloud services.

Materials and methods: The experimental research was carried out at on 306 students of the Bogomolets National Medical University. To perform the set tasks, some theoretical and empirical methods of scientific research were used, namely: system analysis method, bibliosemantic method, statistical method, modeling method.

Results: The expediency of building a hybrid digital environment, which combines the capabilities of the corporate and public cloud service and allows one to create an information system of personalized access to electronic educational resources was justified. This environment is implemented within the cloud service Nextcloud.

The basic components of radiological diagnostics training by means of network technologies are considered and characterized. An experimental test of the effectiveness of the cloud services use is conducted in the process of training radiological diagnostics.

Conclusions: The expediency of creating a modern digital educational environment based on the Nextcloud service for training radiological diagnostics has been justified. Moreover, it is demonstrated that pedagogically balanced and reasoned introduction of cloud services in the educational process promotes increased efficiency of educational process of radiological diagnostics.
\end{abstract}

KEY WORDS: future physicians, radiological diagnostics, cloud services, training, teaching

Wiad Lek. 2021;74(3 p.II):589-595

\section{INTRODUCTION}

\section{FORMULATION OF THE PROBLEM}

One of the priority areas for making positive qualitative changes in medical education is the use of digital and network technologies, which contain powerful information resources and provide multifunctional tools for improving almost all components of the whole educational process. At the same time, the problem of integrated and complex use of network technologies and cloud services in the methodology of teaching radiology to future doctors has not yet been studied. Despite the fact that radiology belongs to the most technological and rapidly changing medical fields, most educational information about radiology needs to be supplemented by visualisation: the series of medical images. Moreover, printed textbooks on radiology, illustrated manuals, and atlases also lack for content that can be quickly and systematically updated. In modern radiology, the processing of a series of medical images that are provided by modern diagnostic systems (e.g., multislice computed tomography, single-photon emission computed tomography, positron emission tomography etc.) is of particular importance.

The understanding of physical and technical bases of methods, the presence of abilities and skills of improving medical images quality, the optimization of radiation exposure conditions provide an opportunity to receive a complex of details of the process prevalence, reaction of adjacent tissues, lymphatic system, and condition of remote organs. All these aspects play a crucial role in more specific modality for further differential diagnosis. Full understanding of the pathological process at the diagnosis stage is not enough to simply identify it in a single image the requirements of modern medicine need more detailed radiological characteristics for further successful treatment. A combination of theoretical knowledge and skills in radiological diagnostics and therapy, normal anatomy, clinical disciplines, information technology, as well as the skills of visual perception of numerous medical images provide the necessary basis for the formation of future doctors' professional competence in terms of applying radiological methods in diagnoses and therapy. This leads to the search for mechanisms to effectively improve the quality of the radiology educational process and didactic potential of digital technologies analysis.

The problems of modern radiological diagnostics have been the subject of research by such scientists as: I. Bilous $[1,2]$, M. Tkachenko [2] and others. The studies of V. Bykov [3], V. Lapinsky [4], P. Mykytenko [5], O. Spirin [6], N. Stuchynska $[7,8]$ and others are devoted to the study of the potential of digital, including network, technologies for improving the quality of the educational process. 


\section{THE AIM}

The aim of the article is to present and substantiate approaches to the organization of radiation diagnostics training using cloud services.

\section{MATERIALS AND METHODS}

To perform the set tasks, some theoretical and empirical methods of scientific research were used, namely: system analysis method, which is used for development of methodological support of teaching the radiological diagnostics basics in accordance with their functions and role in the system of professional training of a future doctor; bibliosemantic method, which is used for studying scientific literature; statistical method, which is used for systematization of theoretical and experimental data, analysis of trends within the methods of radiological diagnostics in modern medicine, processing the results of pedagogical experiments; modeling method, which is used to develop the structure of basic concepts of teaching radiological diagnostics methodology.

The experimental research was carried out at the Bogomolets National Medical University (Kyiv).

The methods of mathematical statistics (testing statistical hypotheses, Pearson's chi-squared test (c2), etc.) were used to establish the reliability of the positive impact and efficiency of the cloud services application in the process of teaching radio diagnostics. The sample is comprised of 306 medical students.

\section{RESULTS}

In radiological research, the use of a wide range of methods based on various physical phenomena, laws and principles, and their constant replenishment with new methods of diagnosis and treatment of socially important diseases significantly modernize and improve the diagnostic and treatment processes. Meanwhile, it reduces treatment time and improves complex and neglected cases. At the same time, it creates a daily challenge to the multimillion-dollar army of doctors whose professional competence must be commensurate with the transformational changes of modern medical theory and practice. The development of radiological methods is closely connected with the development of related fields: information technology, biological physics, medical physics, etc. Thus, the decisive role in the emergence of fundamentally new methods of visualization was played by information technology with the development of a method of layer-by-layer image acquisition (computed tomography).

The ability to conduct examinations using the whole range of available radiological diagnostics methods and choose the optimum way of identifying functional and morphological changes in pathology of various organs and systems and the ability to interpret research results for clinical diagnosis, as well as the ability to use radiation therapy for tumor and non-neoplastic diseases is an integral part of the professional competence of a modern doctor. According to OECD (Organization for Economic Cooperation and Development), there is a growing trend in the number of medical equipment based on the use of X-ray methods for diagnostic purposes in almost all European and world countries including Ukraine.

The results of the data analysis interpreting the time history of the number of radiotherapy equipment (Figure. 1,2) over the recent decade show that there is an equalization (smoothing) of differences in the amount of equipment per one million population due to different growth rates of radiotherapy tools. These data give grounds to predict a significant increase in the number of devices for CT and MRI examinations in Ukraine in the coming years, hence the need for competent specialists for their use. We selected the following countries for comparison: Japan, USA, Australia, Canada, France, Poland, Ukraine. The comparative analysis was carried out within the period of 2009-2019 (Table I).

The data for magnetic resonance imaging devices were collected, analyzed, and graphically represented in a similar way (Table II).

While comparing the statistics within a specific period of time, different rates of increase in the number of radiotherapy equipment become apparent. It can be argued that due to different growth rate of the number of radiotherapy equipment, there is an equalization (smoothing) of differences in the amount of equipment per one million population. These data give grounds to predict a significant increase in the number of devices for CT and MRI examinations in Ukraine in the coming years, hence the demand for competent specialists.

Consequently, mastering the physical and technical basics of radiological methods of diagnostics becomes more relevant and includes:

- knowledge of the physical essence of different phenomena and processes that form the basis of a certain radiological research method;

- understanding of physical and technical basics of designing devices for the needs of radiological research;

- knowledge of methods of image acquisition and its specifics.

Applying cloud services in the process of learning physical and technical basics of radiological diagnostics is both a learning tool and an object of a study because the advent of digital technology era in medical practice has created unprecedented conditions for the visualization of images, allowing to obtain the first computed tomography of brain tumors in 1972. Apparently, the use of new technological means, software products, network hardware and software determines the transformation of the processes related to the main principles of organizing teaching process, their form, content, educational technologies and requires proper didactic support. The substantial component of the educational process is based on the use of electronic and printed sources and aims to ensure shaped educational content. It includes the implementation of educational and methodological support of basic forms of educational activities: lectures, practical classes, independent work, etc. 

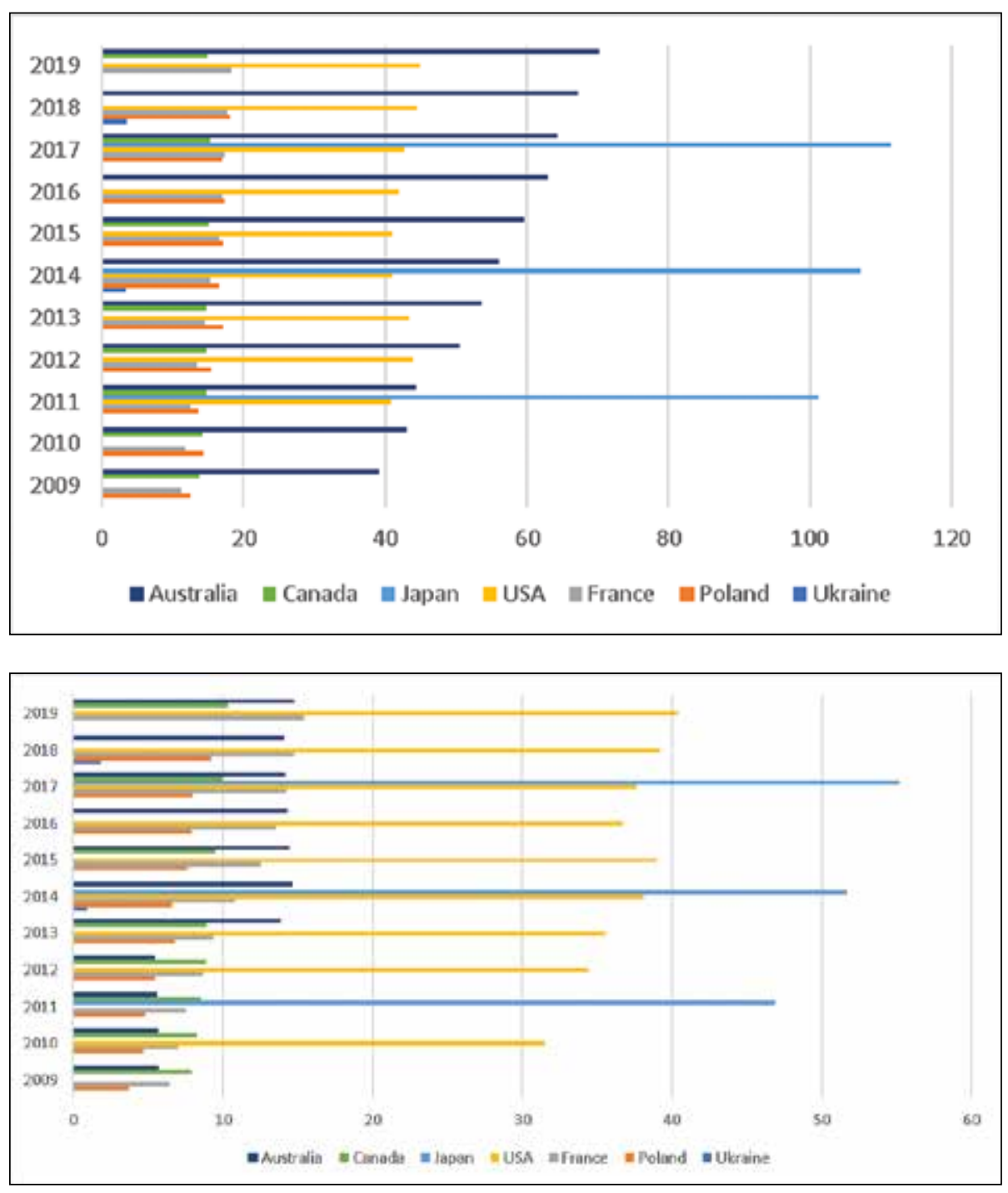

Fig 1. Time history of the number of CT equipment

Fig 2. Time history of the number of MRI equipment
The organizational and methodological component includes: management systems for educational activities, means of information support, feedback, mechanisms of interaction. The management of educational activities involves the management of knowledge acquisition indirectly: a conscious perception of the purpose of educational activities, its subject, the means for its gradual implementation, as well as the knowledge and skills necessary for the work, which are provided by the information competence of a student. The effectiveness of educational activities is largely determined by the conscious acceptance of educational goals and involves systematic monitoring as one of key tools within organizational and methodological component.

The technological component contains a set of hardware and software combined into a system that provides dealing with all types and forms of educational activities. In other words, digital educational environment is a learning environment supplemented by hardware, and software; content and information; methodological, electronic, and network

Table I. Time history of the number of CT equipment (according to data from $[9,11]$ )

\begin{tabular}{cccccccccccc}
\hline CT & $\mathbf{2 0 0 9}$ & $\mathbf{2 0 1 0}$ & $\mathbf{2 0 1 1}$ & $\mathbf{2 0 1 2}$ & $\mathbf{2 0 1 3}$ & $\mathbf{2 0 1 4}$ & $\mathbf{2 0 1 5}$ & $\mathbf{2 0 1 6}$ & $\mathbf{2 0 1 7}$ & $\mathbf{2 0 1 8}$ & $\mathbf{2 0 1 9}$ \\
\hline Ukraine & & & & & & 3,26 & & & & 3,53 & \\
\hline Poland & 12,4 & 14,38 & 13,61 & 15,4 & 17,09 & 16,63 & 17,16 & 17,33 & 16,88 & 18,14 & \\
\hline France & 11,08 & 11,82 & 12,53 & 13,49 & 14,49 & 15,32 & 16,57 & 16,95 & 17,36 & 17,68 & 18,24 \\
\hline USA & & & 40,89 & 43,89 & 43,5 & 41,05 & 41,01 & 41,88 & 42,74 & 44,55 & 44,99 \\
\hline Japan & & & 101,3 & & & 107,2 & & & 111,5 & \\
\hline Canada & 13,8 & 14,23 & 14,62 & 14,69 & 14,77 & & 15,07 & & 15,35 & & 14,82 \\
\hline Australia & 39,14 & 43,07 & 44,32 & 50,5 & 53,66 & 56,06 & 59,54 & 63 & 64,34 & 67,29 & 70,25 \\
\hline
\end{tabular}


Table II. Time history of the amount of MRl equipment (according to data from $[9,11]$ )

\begin{tabular}{|c|c|c|c|c|c|c|c|c|c|c|c|}
\hline MRI & 2009 & 2010 & 2011 & 2012 & 2013 & 2014 & 2015 & 2016 & 2017 & 2018 & 2019 \\
\hline Ukraine & & & & & & 0,92 & & & & 1,88 & \\
\hline Poland & 3,7 & 4,71 & 4,83 & 5,49 & 6,78 & 6,6 & 7,63 & 7,87 & 7,93 & 9,22 & \\
\hline France & 6,43 & 6,96 & 7,51 & 8,65 & 9,4 & 10,86 & 12,56 & 13,55 & 14,21 & 14,77 & 15,43 \\
\hline USA & & 31,52 & & 34,46 & 35,51 & 38,12 & 39,03 & 36,74 & 37,65 & 39,24 & 40,44 \\
\hline Japan & & & 46,86 & & & 51,69 & & & 55,21 & & \\
\hline Canada & 7,91 & 8,26 & 8,53 & 8,87 & 8,89 & & 9,52 & & 10,02 & & 10,35 \\
\hline Australia & 5,72 & 5,67 & 5,6 & 5,5 & 13,84 & 14,65 & 14,49 & 14,3 & 14,15 & 14,09 & 14,78 \\
\hline
\end{tabular}

Table III. Frequency distribution in control (CG) and experimental (EG) groups

\begin{tabular}{|c|c|c|c|c|c|c|c|c|c|c|c|c|c|c|c|}
\hline \multirow[b]{2}{*}{ № } & \multirow[b]{2}{*}{ Group } & \multirow[b]{2}{*}{ 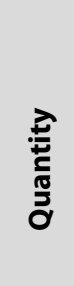 } & \multicolumn{4}{|c|}{ Empirical frequency (p) } & \multicolumn{4}{|c|}{ Theoretical frequency ( $\left.p^{\prime}\right)$} & & \multirow{2}{*}{\multicolumn{2}{|c|}{$\frac{\left(\boldsymbol{p}-\mathbf{p}^{\prime}\right)^{2}}{\mathbf{p}^{\prime}}$}} & & \multirow[b]{2}{*}{$\Sigma$} \\
\hline & & & 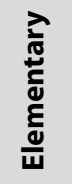 & $\begin{array}{l}\frac{u}{y} \\
\stackrel{\Xi}{J}\end{array}$ & 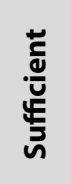 & 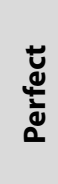 & 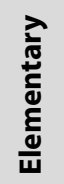 & 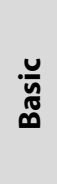 & 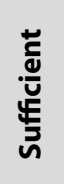 & 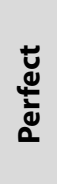 & & & & & \\
\hline 1 & CG & 151 & 14 & 66 & 56 & 15 & 10 & 58 & 62 & 20 & 1,277 & 1,037 & 0,614 & 1,138 & 4,065 \\
\hline \multirow[t]{2}{*}{2} & EG & 155 & 7 & 52 & 70 & 25 & 11 & 60 & 64 & 20 & 1,244 & 1,010 & 0,598 & 1,108 & 3,960 \\
\hline & $\Sigma$ & 306 & 21 & 118 & 126 & 40 & & & & & & & & $x^{2}$ & 8,025 \\
\hline
\end{tabular}

resources and technologies; and cloud services. All the mentioned elements combined together create fundamentally new opportunities for organizing the learning process. The recommendations of the National Institute of Standards and Technology (NIST) [11] state that cloud services serve a model for providing ubiquitous and convenient on-demand access over a network to a common database of configurable computing resources that can be provided quickly with minimal management costs and with rare appealing to provider. The mentioned interpretation describes precisely what the true cloud services really are. One of the advantages of learning tools focused on the use of network and cloud services is the implementation of the principle of clarity in its modern sense. It should be noted that these technologies are exceptionally productive in academic disciplines, where visualization is an important component. Students learn to analyze the results of radiological studies and to assess the norms and pathologies of various organs and systems on their basis. Such knowledge and skills depend on visual perception of the educational material; and the skills of diagnosis, being an important component of professional competence, can be formed only by continuous repeating the same procedures. The indicators of the effectiveness of applying cloud services in the process of teaching of radiological diagnostics include:

- creation of the skills of diagnosing by means of radiological methods;

- assessment of educational achievements;

- organization of productive independent work;

- organization of cooperative training and work in groups;
- solving specific tasks;

- organization of blended learning and other innovative learning technologies;

- production of educational presentations and other visual materials;

- development of software applications to improve learning efficiency;

- organization of access to educational software.

The feasibility of choosing cloud services as a factor of improving the efficiency of teaching medical students, modernization of the educational process, professionally oriented content of the educational environment, diagnosis and monitoring of their educational achievements start to play a key role.

There are several cloud services for the organization of educational process to be distinguished among all the available ones in global network, namely GoogleDrive, Dropbox, Microsoft OneDrive, and Mega. However, these services do not allow to implement a system that would contain data on a local server without involving any third-party data centers and would have an integrated DICOM viewer of medical images.

One of the possible means of organizing the training process of radiological diagnostics is the Nextcloud service (open-source file synchronization system that enables to share content, software and applications with all registered users within a secure dedicated server).

Based on the Nextcloud service with such parameters as compatibility with equipment, ease of access, ease of use, utility, stability, content quality, and productivity for independent work, the functional characteristics of the cloud training resource on radiology was professionally assessed. 

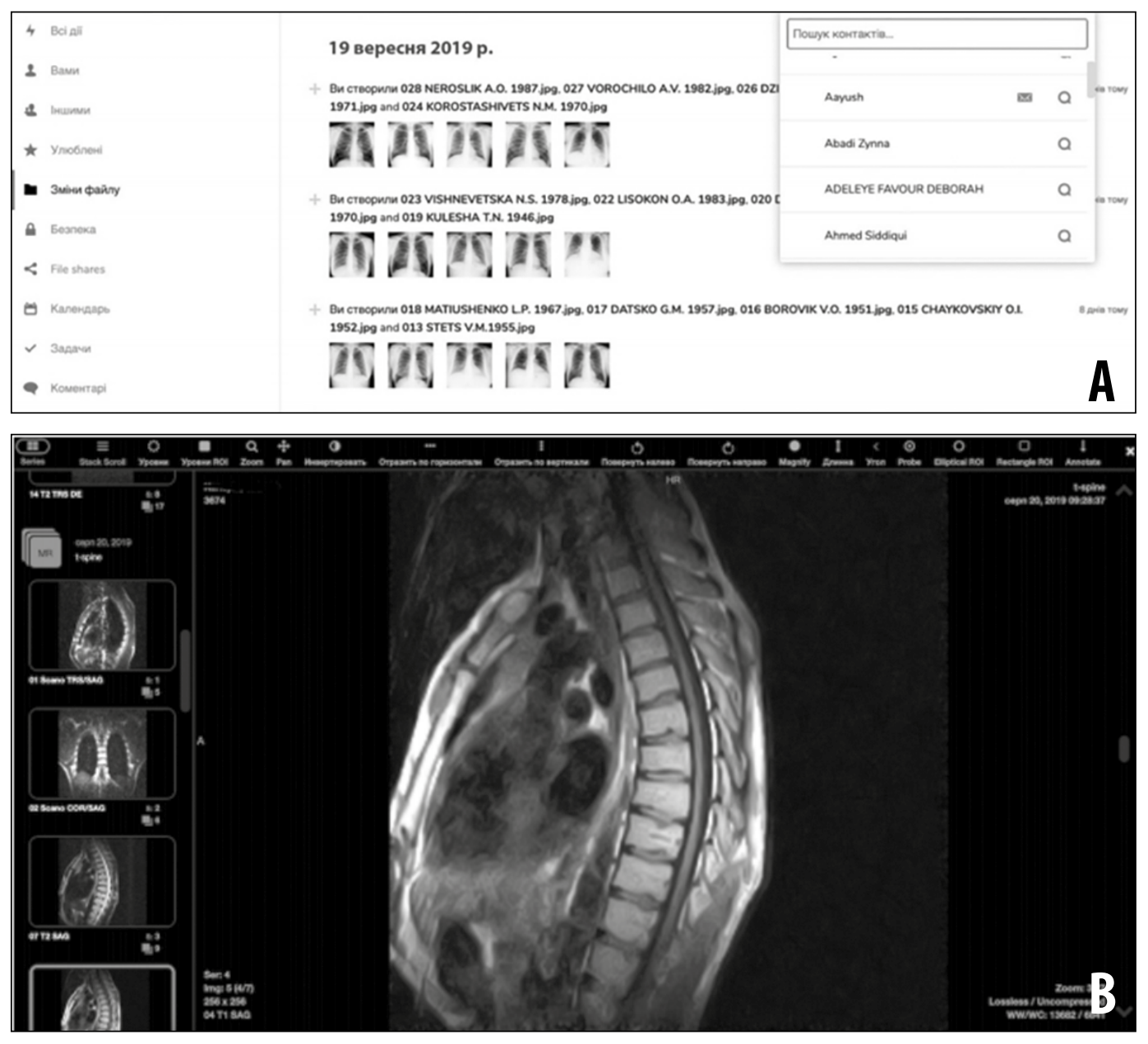

Fig. $3(A, B)$. Nextcloud user interface (DICOM viewer tab)

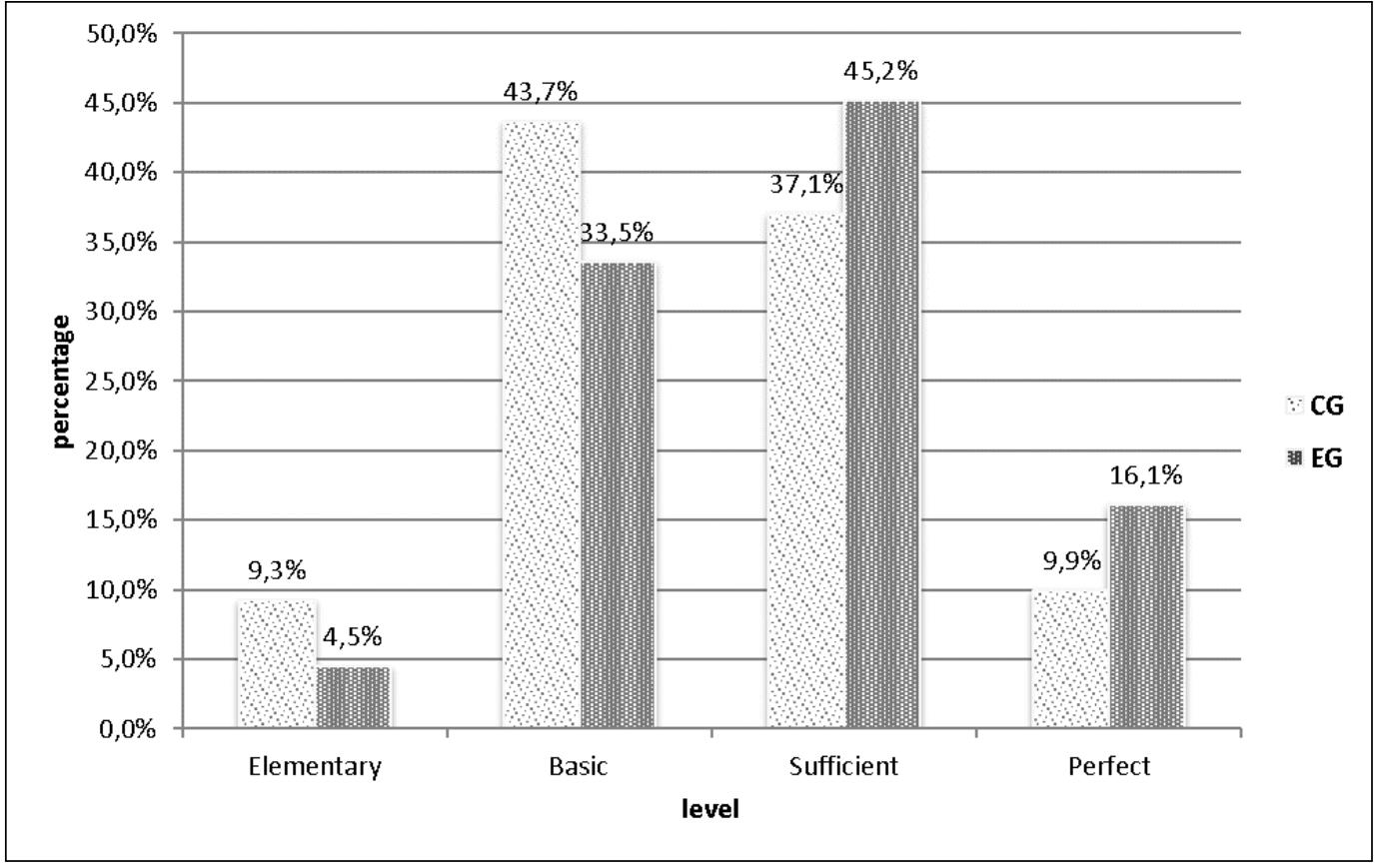

Fig 4. Frequency distribution in control $(C G)$ and experimental (EG) groups

The latter made it possible to establish a final score of 8.9 on a ten-point scale, which is a reason to recommend it for further implementation and use.

There are the following advantages of the system designed on the basis of the Nextcloud service:
- the universal ability to connect to the server using any web browser (Mozilla Firefox 14+, Google Chrome/Chromium 18+, Safari 7+, Internet Explorer 11+, Microsoft Edge);

- the volume of the cloud file storage for an individual user is set by the administrator (teacher) and can be changed if necessary; 
- the study groups are administered by a teacher who is able to block, restrict or expand access to the resources according to individual capabilities and needs of students (academic debt, research work, group projects, etc.);

the shared use and processing one or more files on a computer and synchronizing them with the server;

- the ability to place files in local shared directories and synchronize them with the server and other devices using the Nextcloud Desktop Sync client or Android or iOS software, which are available for download in Google Play and AppStore;

- editing Microsoft Word documents, Microsoft Excel spreadsheets and Microsoft PowerPoint presentations with the built-in OnlyOffice application;

- demonstrating medical images in DICOM format (Digital Imaging and Communications in Medicine medical industry standard for creation, storage, transmission, and visualization of digital medical images and documents of the examined patients) using the built-in DICOM viewer application, which provides basic tools for working with medical images and their series. Ultimately, it forms an unprecedented objective idea of the possibilities of modern methods of radiological diagnostics among students (Figure 3).

\section{DISCUSSION}

Thus, we managed to create a digital educational environment, which provided rather powerful tool for shaping professional competence of future doctors in radiological diagnostics: cloud-based educational information network for sharing; virtualized systems to support learning interaction, which contain publicly available online collections of electronic educational resources and services; cloud-oriented corporate information system, which provides selective access of various user groups to a flexibly organized pool of electronic educational resources; high-quality video and audio communications; instant messaging services; cloud-oriented systems of real-time interaction; personalized access of students to educational resources and software; information and analytical network systems; control systems for coordinating activities and interaction of users in the learning processes; specialized software (programs for visualization and transmission of medical images, statistical processing of results, etc.).

Since the study of medical imaging is one of the most effective methods of obtaining visual data on the internal structure and functions of the human body, and modern medical diagnostics is inextricably linked with the visualization of internal structures of biomedical objects, it becomes reasonably to use services that have applications for processing images in DICOM format. Students have the opportunity to know more and work with means of acquiring medical images, to learn how to interpret its methods, and to analyze samples and objects of medical images.

The personification of the educational environment made it possible to assess the usefulness of software products and information resources, students' academic achievements, the level of their educational activity. It also helped to analyze the reasons for which learning outcomes are determined, to stimulate and organize educational activities because all the user actions (reviewing materials, dealing with tests, etc.) or inactivity are automatically fixed by the system and are observed by the teacher, which is an indirect imperative for the the orderliness and scrupulosity of students.

In order to establish the reliability of a positive impact of the use of cloud services in the process of learning radiological diagnostics in the experimental group (EG) and compare it with the control group (CG) (Figure 4), the Pearson's chi-squared test (c2) was applied.

The null hypothesis $\mathrm{H}_{0}$ showed that the probability of students from control and experimental groups falling into each of $t$ categories accidentally $(t=1,2,3,4$ for both samples) are equal, and the highest level of knowledge of radiological diagnostics in experimental group can be explained with random factors. Alternative hypothesis $\mathrm{H}_{1}$, in its turn, indicated that $\mathrm{p}_{1 \mathrm{i}} \neq \mathrm{p}_{2 \mathrm{i}}$ at least for one of the groups, and the higher level of knowledge cannot be explained with the peculiarities of sampling but can be determined by the use of innovative technologies in the process of teaching radiological diagnostics. To test the null hypothesis using the criterion $\mathrm{c}^{2}$, the value of the criterion $\chi_{\text {emp }}^{2}$ statistics (Table III) is set at the accepted level of significance $(\alpha=0.05)$

After the experiment, experimental and control groups had statistically significant differences because the critical value of $\chi_{c r}^{2}=7,815$ for the number of degrees of freedom $\mathrm{n}=\mathrm{C}-1=4-1=3$ at the level of significance $\alpha=0.05$. In this case, $\chi_{\text {emp }}^{2}=8.025$ and $\chi_{\text {emp }}^{2}>\chi_{c r}^{2}$, which gives grounds for rejecting the null hypothesis.

Thus, the analysis enables to test the hypothesis of the study and establish that the quality of teaching physical and technical basics of radiological diagnostics has improved among the students of medical institutions of higher education as a result of using the Nextcloud service.

\section{CONCLUSIONS}

Based on statistical data, there is a distinct trend towards increasing the number of medical equipment and research using radiological methods and the growing role of non-invasive technologies: ultrasound, CT and MRI, radionuclide methods - positron emission tomography. It challenges medical education as the physicians' professional competence must meet the needs of modern medical theory and practice.

The expediency of creating a modern digital educational environment based on the Nextcloud service for training radiological diagnostics has been justified. Moreover, it is demonstrated that pedagogically balanced and reasoned introduction of cloud services in the educational process promotes increased efficiency of educational process of radiological diagnostics. 


\section{REFERENCES}

1. Belous I.V., Stuchynska N.V. Blended learning of the basics of radiological diagnosis by future doctors. East European Scientific Journal. 2019; 6(46):52-55.

2. Belous I.V., Stuchynska N.V., Tkachenko M.M. Learning the basics of radiation diagnostics using network technologies. Theoretical and methodological problems of raising children and students. Collection of scientific works. Kyiv: Gnosis. 2017; 1(75):17-32. (In Ukrainian).

3. Spuziak M.I., Kramnyi I.0. Actual problems of preparation of radiological diagnostics. Problems of modern medical science and education. 2010;2:7-8. (In Ukrainian).

4. Dutka I.Yu. Problems of radiological diagnostics in the context of medical services in various fields of health care. Bulletin of Scientific Research, 2017;2:165-169. (In Ukrainian).

5. BykovV.Yu. Cloud technologies, ICT outsourcing and new functions of ICT units of educational and research institutions. Information technology in education. 2011;10:8-23. (In Ukrainian).

6. Lapinskyi V.V., Mykytenko P.V. Designing interdisciplinary integration of medical informatics Information technologies and Learning tools. 2020; 1(75):26-41. doi: https://doi.org/10.33407/ittt.v75i1.3569. (In Ukrainian).

7. Mykytenko P.V. Using cloud services in solving logical problems. Information technologies and Learning tools. 2017;1(57):104-114. doi: https://doi.org/10.33407/ittt.v57i1.1503. (In Ukrainian).

8. Spirin 0.M., Vakaliuk T.A. Criteria for selection of open web-oriented technologies for teaching the basics of programming to future computer science teachers. Information technologies and Learning tools. 2017;4 (60):275-287. (In Ukrainian).

9. Stuchynska N.V., Ostapovych N.V., Belous I.V. Game-based technologies in teaching professionally oriented natural sciences to the future doctors. Revista tempos em spagos educacao. 2020;31:160-175. doi: 10.32930/ nuances.v31i0.8215.

10. Stuchynska N.V. Teaching medical and biological physics by ICT: analysis of the experience of implementing. Information technologies and teaching aids. 2012; 6(32). Access mode: http://www.journal.iitta.gov. ua. (In Ukrainian).

11. OECD, Computed tomography (CT) scanners (indicator) and magnetic resonance imaging (MRI) units (indicator). doi: 10.1787/bedece12-en.
12. Center for Medical Statistics of the Ministry of Health of Ukraine http:// medstat.gov.ua/ukr/statdan.html.

13. The NIST Definition of Cloud Computing. Recommendations of the National Institute of Standards and Technology. http://csrc.nist.gov/ publications/nistpubs/800-145/SP800- 145.pdf.

The article was performed in framework of research "Methods of training the basics of radiology and radiation therapy for future doctors with the use of information society technologies ", (2017-2019, № state registration 0117U002264).

\section{ORCID and contributionship:}

Nataliia V. Stuchynska: 0000-0002-5583-899X A, B, C, D, E, F Igor V. Belous: 0000-0002-9150-484X ${ }^{A, B, C, D, E, F}$

Pavlo V. Mykytenko: 0000-0003-1188-4334 ${ }^{B, C, D}$

\section{Conflict of interest:}

The Authors declare no conflict of interest.

\section{CORRESPONDING AUTHOR Nataliia V. Stuchynska}

Bogomolets National Medical University 34 Peremohy Ave, 03680 Kyiv, Ukraine tel:0503566057

e-mail:nvstuchynska@gmail.com

Received: 10.10 .2020

Accepted: 04.03.2021

A - Work concept and design, B - Data collection and analysis, C - Responsibility for statistical analysis, D-Writing the article, $\mathbf{E}$-Critical review, $\mathbf{F}$ - Final approval of the article 